\title{
Discurso sobre a Ciência na emergência histórica da "Rede Nacional de Educação e Ciência"
}

\section{Resumo}

Lavínia Schwantes

Paula Corrêa Henning

Paula Regina Costa Ribeiro

Universidade Federal do Rio Grande

62 Palavras-chave: Ciência. Análise do discurso. Divulgação da ciência.

\section{Discourse on Science in the historical emergence of the "National Network of Education and Science"}

\section{Abstract}

Different projects that promote the access to science through the education have been developed such as the National Network of Education and Science, which aims to improve the access to science and its teaching through courses for teachers and students from public schools. We aim to establish the initial speech of science of this Network. The methodology employed concepts and tools from Foucault's discourse analysis. We have listening three enunciations that characterize the initial speech of science of this Network: doing science involves a path for generating "new" publishable products; scientist formation in the innatism and empiricism dyad; scientist formation by social inclusion. These enunciations can be understood as conditions of possibility for the emergence of the Network and they are powerful ways of developing and producing science nowadays.

Keywords: Science. Discourse analysis. Science dissemination. 


\section{Discurso sobre la Ciencia en la emergencia histórica de la "Rede Nacional de Educação e Ciência"}

\section{Resumen}

EDiferentes proyectos para la promoción del acceso a la ciencia por medio de la educación se han desarrollado, como la "Rede Nacional de Educação e Ciência" que tiene como objetivo ampliar el acceso a la ciencia y a la enseñanza a través de cursos para profesores y alumnos de la educación pública. Intentamos comprender el discurso inicial de "ciencia" de la "Rede". La metodología empleó conceptos y herramientas del análisis del discurso foucaultiano. Se eligió tres enunciados como el eje de dicho discurso científico en la emergencia de la "Rede": hacer ciencia exige un camino capaz de generar nuevos productos publicables; la formación del científico entre el innatismo y el empirismo; formación de científicos gracias a la inclusión social. Estos enunciados son comprendidos como condiciones de posibilidad para la emergencia de la Rede al mismo tiempo que son modos potentes para el desarrollo y la producción de ciencia en la actualidad.

Palabras clave: Ciencia. Análisis del discurso. Divulgación de la ciencia.

\section{Introdução}

A ciência, alicerçada por seu método, suas técnicas, suas demonstrações e suas descobertas, desde sua emergência no século XVII com Descartes, Bacon e Galileu, entre outros, tem estado em pauta nas discussões sobre a produção do conhecimento. Diferentes formas de conceber a ciência foram produzidas por estudiosos, filósofos e cientistas, até a consagração da ciência.

Por suas características - dogmática, quantificável, experimental e determinista -, a ciência, segundo Michel Foucault (201 1), constitui o campo de conhecimento que foi o grande regime de verdade na episteme da modernidade. Para Paula Henning (2010, p. 57, grifo da autora), "[...] na busca por bases sólidas para o conhecimento e desvelamento do mundo, esse conhecimento legítimo produziu-se por uma nova ordem, cada vez mais fixa [...]" que acredita "[...] superar os conhecimentos divinos, fazer desse conhecimento algo tão absoluto e útil e, ainda, como um conhecimento neutro, puro, favorecer de chegarmos a saber o que é mesmo essa realidade". Esse padrão rígido envolveu a determinação de um campo de saber, uma metodologia de 
Discurso sobre a Ciência na emergência histórica da "Rede Nacional de Educação e Ciência"

pesquisa e uma forma de generalização dos resultados. Ainda definindo a ciência por sua vontade de saber, Foucault destaca que:

[...] por volta do século XVI e do século XVII (na Inglaterra, sobretudo), apareceu uma vontade de saber que, antecipando-se a seus conteúdos atuais, desenhava planos de objetos possíveis, observáveis, mensuráveis, classificáveis; uma vontade de saber que impunha ao sujeito cognoscente (e de certa forma antes de qualquer experiência) certa posição, certo olhar e certa função (ver, em vez de ler, verificar, em vez de comentarl; uma vontade de saber que prescrevia (e de um modo mais geral do que qualquer instrumento determinado) o nível técnico do qual deveriam investir-se os conhecimentos para serem verificáveis e úteis (FOUCAULT, 201 1, p. 16).

Na contemporaneidade, também devido às novas configurações de espaço e tempo, filósofos e pensadores têm questionado esse espaço de legitimidade ocupado pela ciência, colocando-a como uma das formas de produção de saber. Deste modo, a posicionam como uma produção cultural (WORTMANN; VEIGA-NETO, 2001), problematizam seus métodos considera64 dos deterministas e universais (FEYERABEND, 2007; SHAPIN, 2013) e articulam sua produção dentro de um contexto social, histórico e político (LATOUR, 2000; FOUCAULT, 2009).

Mesmo com essas problematizações, em nossa atualidade, as características que conferem legitimidade à ciência ainda possibilitam que esse campo de conhecimento tenha potência na produção das verdades de nossa sociedade. Desse modo, a ciência vem tendo atenção, desde a primeira década do século XXI, de acadêmicos de várias áreas, de instituições financiadoras e de órgãos governamentais tanto em relação ao incentivo à produção científica em laboratórios de pesquisa, quanto em relação à divulgação científica, ao acesso à ciência e às discussões e problematizações sobre seu ensino. Recentemente, em 2013, o Ministério da Educação, por exemplo, depois de um período de preocupação com a alfabetização, tanto de língua portuguesa quanto de matemática, tem mostrado interesse no ensino de ciências ao incluir os conteúdos da área numa das provas de avaliação do ensino na Educação Básica brasileira, a Prova Brasil' (BRASIL, 2010).

Esse interesse tem sobressaído por inúmeros motivos, entre os quais, o fato de que conhecer a ciência, para o estudante, é uma possibilidade 
de desenvolvimento intelectual e de ampliação de seu campo de atuação na sociedade, viabilizando seu pleno exercício de cidadania (BRASIL, 1998). Além disso, os Parâmetros Curriculares Nacionais do Ensino Médio (BRASIL, 1998) destacam também a importância do uso de metodologias mais ativas no ensino de ciências, que coloquem os estudantes no centro de sua obtenção de conhecimento e desenvolvimento, como, por exemplo: observações, experimentação, jogos, uso de diferentes fontes textuais para obtenção e comparação de informações, como revistas, sítios da internet, jornais. Esses exemplos atraem o interesse dos estudantes pelos conteúdos e conferem à ciência sentidos que não são possíveis caso ela seja estudada apenas em um livro ou por meio da fala do professor como, por exemplo, a apropriação de questões éticas e sociais envolvendo os produtos gerados pela ciência, o questionamento à neutralidade da produção científica e a geração de discussão sobre o alcance da ciência na atualidade, entre outros.

Entendemos que, a partir desses movimentos, vem ocorrendo a ampliação dessas discussões sobre a ciência como área de saber e sobre o ensino científico, consideradas a partir das inúmeras vertentes epistemológicas, pedagógicas, científicas, filosóficas de ciência e de educação. Também vem aumentando o incentivo a diferentes projetos financiados por instituições governamentais tanto federais como estaduais, interessadas na ampliação da produção científica e na melhoria do ensino na área.

Entre esses projetos, neste artigo, centramo-nos no programa da Rede Nacional de Educação e Ciência: Novos Talentos da Rede Pública (RNEC/ NT)2, iniciada na Universidade Federal do Rio de Janeiro (UFRJ), em 1985. Inicialmente, constituía-se num grupo de pós-graduandos e graduandos, sob coordenação de um pesquisador reconhecido pela sua comunidade acadêmica e científica, que promovia cursos de férias sobre o método científico para professores e alunos da rede escolar. A primeira parceria estabelecida para dar início à Rede foi com um grupo da Universidade Estadual de Campinas (UNICAMP) que perdurou dez anos. Eram dois grupos cujos coordenadores eram pesquisadores de áreas específicas das Ciências Biológicas - Bioquímica, no caso da UFRJ, e Genética, no caso da UNICAMP - que procuravam trabathar o método científico em cursos para alunos e professores. É interessante destacar que os assuntos desenvolvidos nesses cursos são sempre vinculados às áreas de pesquisa específica dos coordenadores de grupo envolvidos. 
A ampliação posterior da RNEC foi realizada por convite destes dois grupos iniciais. Atualmente, essa Rede conta com mais de 45 grupos de pesquisadores em 23 universidades e institutos de pesquisa brasileiros e tem como pressuposto "[...] a melhoria das condições de ensino de ciências a jovens de todo o país" (REDE, 2015). Os grupos vinculados a essa Rede atuam de duas formas: proporcionam estágios em laboratórios e grupos de pesquisa para estudantes carentes da Educação Básica, e oferecem cursos direcionados a estudantes e a professores desse nível de ensino, no estilo dos cursos promovidos desse o início da formação da Rede. O principal objetivo da RNEC/NT é "[...] buscar novos caminhos para um ensino eficiente. Para isso, desenvolve metodologias que facilitam o aprendizado, desmistificando a ciência" (REDE, 2015 ). Esse objetivo também possibilita que os grupos se atualizem em seus entendimentos de ciência e método, e desenvolvam essas discussões nas atividades vinculadas à Rede.

Esse programa da RNEC/NT chama-nos atenção devido à visibilidade que tem recebido nos últimos anos, a ponto de uma agência de fomento brasileira, a Coordenação de Aperfeiçoamento do Pessoal de Nível Superior (Capes), ter formulado um edital específico - Edital Novos Talentos, nos anos

66 de 2010, 2012 e 2014 - para financiamento de outros projetos de melhoria do ensino de ciências, baseado nas ideias, objetivos e metodologias da RNEC/NT. Por isso, toma-se a RNEC/NT como objeto de uma Tese cujo problema de pesquisa é como se constitui o discurso científico em grupos da RNEC/NT.

Com base no exposto, neste artigo, pretendemos estabelecer discurso inicial de ciência dessa Rede, apontando alguns enunciados que podem caracterizar as balizas deste discurso. Para alcançarmos este objetivo, utilizamos as entrevistas para produção de dados e, para análise dos mesmos, algumas ferramentas de análise do discurso foucaultianas, como discurso, enunciação e enunciado, explicadas a seguir.

\section{Sobre a produção e análise dos dados: entrevistas e análise do discurso}

Para a produção de dados: entrevistamos o idealizador do programa da RNEC/NT e primeiro coordenador do grupo da UFRJ; o primeiro aluno 
"jovem talentoso" a estagiar no laboratório de pesquisa desse grupo e atual coordenador do programa na UFRJ. Também foi entrevistado o coordenador do grupo da segunda universidade a integrar a Rede, a UNICAMP. Além deles, foram entrevistados outros dois professores da Universidade Federal do Rio Grande do Sul (UFRGS), uma das terceiras universidades a compor a Rede: o atual coordenador do grupo e uma professora, ex-coordenadora das primeiras atividades do mesmo grupo. Totalizamos cinco entrevistas.

$\bigcirc$ uso de entrevistas como metodologia de produção de dados de pesquisa permite que, através de uma narrativa, o entrevistado revisite algumas vivências e projetos que desenvolveu durante a vida acadêmica, mesclando nisso pensamentos e reflexões. As enunciações proferidas nas entrevistas não são aqui tomadas como a verdade sobre os fatos e, sim, no caminho do que traz Sandra Andrade (2012, p. 175), "[...] pode-se considerá-las como a instância central que, somada às outras, traz informações fundamentais acerca do vivido e possibilita uma interpretação (mesmo que provisória e parcial)". As enunciações das entrevistas constituem um efeito de muitos discursos que se colocaram como verdadeiros naquele momento por aqueles sujeitos que falavam. São esses discursos, no entendimento foucaultiano, que, articulando-se entre si, possibilitam a formação de campos de saber como aqui, neste estudo, o da ciência.

As entrevistas foram realizadas nas universidades dos envolvidos entre 2011 e 2013 e gravadas em vídeo. As conversas envolveram questões sobre o programa da RNEC/NT, sobre ciência, sua produção e o seu respectivo ensino no país. Cada entrevista era semiestruturada com algumas questões norteadoras. Por isso, desenvolveu-se de forma mais livre, sem uma sequência linear predeterminada, conforme o diálogo com os envolvidos prosseguia. Posteriormente, as falas foram transcritas na forma de texto para a análise deste trabalho.

Tomando as entrevistas como material discursivo, assumimos, a partir dos estudos foucaultianos, algumas ferramentas da análise do discurso empreendida por esse autor. As condições de aparição de um objeto de análise - aqui, neste trabalho, a ciência na RNEC/NT - são múltiplas e importantes, o que significa que não se pode falar de qualquer coisa em qualquer época de qualquer maneira (FOUCAULT, 2009b). Assim, escolhemos aqueles enunciados que, a partir de uma regularidade e uma inter-relação entre si, amparam o discurso inicial de ciência dessa Rede. 
Nas palavras do autor, "[...] o que pertence propriamente a uma formação discursiva e o que permite delimitar o grupo de conceitos, embora discordantes, que the são específicos, é a maneira pela qual esses diferentes elementos estão relacionados uns aos outros" (FOUCAULT, 2009b, p. 65-66). Uma formação discursiva envolve certo número de enunciados cuja regularidade pode compor um determinado discurso. $\bigcirc$ enunciado é mais que uma palavra escrita ou falada, ou uma coisa; ele se constitui numa função de existência, cuja análise nos permite decidir se ele faz sentido e decidir de quais regras de formação faz parte. Assim, procuramos, a partir da produção de três enunciados, compor o discurso de ciência que baliza a emergência da RNEC/ NT. Nesse sentido, "[...] chamaremos de discurso um conjunto de enunciados, na medida em que se apoiem na mesma formação discursiva" (FOUCAULT, 2009b, p. 1321.

Por se constituir em uma função, não encontraremos esses enunciados explicitamente postos nas entrevistas dos coordenadores, pois a análise dos enunciados é mais que a análise linguística, dos signos; o enunciado não tem uma estrutura semântica ou sintática. Como um "[...] enunciado é sempre um acontecimento" (FOUCAULT, 2009b, p. 31 ), o que aparece dito nessas entre68 vistas é considerado enunciação. As enunciações, sim, são o que está dito nas entrevistas, pois "[...] diremos que há enunciação cada vez que um conjunto de signos for emitido" (FOUCAULT, 2009b, p. 1 14). Cada uma dessas falas, desses conjuntos de signos tem uma individualidade espaço temporal e uma correlação com o sujeito que fala, com seu lugar institucional e com sua posição em relação ao objeto de que fala. Por isso, podemos afirmar que a enunciação pode ser compreendida pela expressão daquilo que o entrevistado disse. Devemos nos centrar no que é dito, na superfície e não no que está por trás, escondido, à espera de ser descoberto.

Assim, entendemos que aquilo que os entrevistados apresentaram em suas falas constitui parte da rede discursiva em que estão entremeados e que, naquele momento, tais enunciações configuravam a verdade sobre suas concepções de ciência da RNEC/NT. Verdade essa entendida, na esteira foucaultiana, como aquela que pertence a um tempo e a um contexto de formação e não como a definitiva, a permanente e a única representante possível do real.

Do conjunto de enunciações mencionadas pelos três primeiros integrantes $^{3}$, compusemos três enunciados: fazer ciência envolve um caminho e a 
geração de produtos "novos" e publicáveis; a formação do cientista na díade inatismo e empirismo; formação do cientista pela inclusão social - cujas análises caracterizam as balizas do discurso inicial dessa Rede.

Postas essas demarcações teóricas e metodológicas, passemos à análise do material para a constituição de cada enunciado, tomando como objetivo deste artigo problematizar como se constitui o discurso inicial de ciência Rede Novos Talentos. Entendemos assim que esse discurso propicia a demarcação de um saber específico, uma forma de se produzir a ciência na atualidade. Para Foucault (201 1), a produção de um saber específico inicia-se a partir de inúmeros discursos que, obedecendo às regras de formação, imprimem um sentido a esse campo de estudo e, ao mesmo tempo, constituem as limitações do mesmo, colocando-o numa ordem discursiva que estabelece e determina aquilo que é considerado verdadeiro.

\section{Constituição do discurso inicial de ciência na emergência da RNEC/NT}

\section{Enunciado 1: Fazer ciência envolve um caminho e a geração de produtos "novos" publicáveis}

Como definido por Foucault (2009b), o enunciado é sempre um acontecimento, não está explícito no texto analisado. Ele configura a partir de recorrências e divergências enunciativas que compõem um discurso emergente em um determinado contexto histórico. Portanto, nesse primeiro enunciado, é importante relacionarmos as posições de sujeito na formação do discurso inicial da RNEC/NT: quem são estes sujeitos que falam; quais seus lugares institucionais; e quais suas posições frente ao objeto que estudam.

Os três entrevistados são posicionados: como sujeitos cientistas de laboratório renomados em suas áreas; como sujeitos pesquisadores pertencentes a universidades reconhecidas internacionalmente; e como sujeitos que pesquisam, "fazem ciência", publicam seus resultados e são preocupados com o alcance da ciência na população e com a geração de novos cientistas. Mesmo com essas semelhanças, cada um dos pesquisadores aponta diferentes formas de entender esse caminho - o método científico - que conduz 
à produção científica. Em função do espaço restrito deste texto, entre muitas enunciações, exemplificamos essa questão, trazendo algumas:

Então ciência é isso. Para mim, ciência é isso: um enorme prazer em descobrir algo novo, ligar os fatos e os pontos que, aparentemente, são desconexos para a grande maioria das pessoas, mesmo os que trabalham na área. Mas, de repente, você olha e encontra um sentido (P3, 201 1)

'O Método Científico' foi o primeiro livro, mas a ideia geral é mais do que isso. Depois apareceram todos esses nomes complicados como Base Problema [...]. Do método, mas isso a gente já fazia naquela época, mas intuitivamente que nós fazíamos, era uma questão de honestidade fazer [usar o método científico]. A única coisa que eu posso fazer é ajudar fazendo o que eu sei fazer [pesquisa no laboratório] (P1, 2011 ).

Pensando numa deficiência do professor de ciências que vai dar aula de ciências e nunca fez ciência. $\bigcirc$ cara nunca pipetou, não sabe nem fazer um experimento. Aí fala 'não, esse cara tem que tomar contato'. Não estou querendo que esse cara venha fazer ciência, não é isso. Mas ele precisa entender metodologia científica mais do que uma aula teórica de metodologia científica (P2, 20111 .

Na hora que você usa o método científico para comprovar se aquilo faz realmente sentido, você descobre que faz e então isso pra mim é a coisa mais gratificante que existe (P3, 2011 ).

Normalmente o que acontece é, por exemplo, no meu caso [e no caso de outros colegas], a gente atua na área de pesquisa, na área de bancada mesmo (P2, 2011 ).

Então são bits de informação, bits de conhecimento que estão lá, mas da forma como elas estão, não fazem o menor sentido. É uma forma um pouco diferente de pensar de algumas décadas atrás, [pois] de vez em quando a gente fica olhando as coisas e, de repente, saem coisas que estão lá no banco de dados: uma informação que eventualmente ela é solta! Mas então, ela vai necessitar de que a gente precise olhar tudo isso e conectar, fazer sentido (P3, 20111 . 
Desde nossas primeiras incursões escolares, aprendemos a pensar a ciência nos moldes do método científico moderno, baseado no racionalismo de René Descartes (2008) e no empirismo de Francis Bacon (1 984). $O$ discurso do método instaurado por esses dois pesquisadores, no século XVII, ainda sustenta, em grande parte, a concepção de ciência na contemporaneidade. Dessa forma, para uma pesquisa ser considerada científica, ela tem de se embasar em um método; daí, a primeira parte do enunciado: fazer ciência envolve um caminho.

Todas as entrevistas trazem essa questão, no entanto, o modo de definir esse caminho apresenta traçados diferentes nas falas de cada um dos entrevistados.

A questão da utilização do laboratório e da experimentação como metodologia científica vincula-se ao empirismo baconiano cuja recomendação àqueles que quisessem saber algo de verdadeiro a respeito da natureza era pesquisar experimentalmente (BACON, 1984). Para o autor, o verdadeiro filósofo natural (expressão usada na época para designar o cientista da natureza) deveria seguir o exemplo da abelha e trabalhar na acumulação sistemática do conhecimento. Sobre a ênfase que dá à experimentação, ele afirma "[...] pretendemos deduzir das obras e experimentos as causas e axiomas e depois, das causas e princípios, novas obras e experimentos, como cumpre aos legítimos intérpretes da natureza" (BACON, 1984, p. 76).

Podemos, ainda, assinalar a atualização do propósito experimental proposto por Bacon séculos atrás com o entendimento de pesquisadores atuais como Alan Sokal e Jean Bricmont (2010), ambos professores universitários de Física. Para eles, os cientistas que praticam a ciência moderna buscam realizar suas pesquisas por um caminho mais cuidadoso e sistemático que as pessoas comuns, pois usam controles estatísticos e insistem na repetição de experiências sempre que possível.

○ caráter experimentalista é bem marcado nas enunciações de Pl e P2 no discurso da RNEC/NT e corresponde à visão mais tradicional de ciência e de muitos cientistas como Sokal e Bricmont (2010) que enaltecem e reforçam a díade ciência-método, salientando a competência com que o método científico desenvolve o conhecimento sobre o mundo. Essa ênfase na experimentação emergiu com o empirismo de Bacon, no século XVII, cuja ênfase centrava-se na indução, nesse processo pelo qual por meio da observação e 
da experimentação se entenderia o que era estudado. "Na visão indutivista, o método científico parte da observação à elaboração de hipóteses, seguida de experimentos (repetidos diversas vezes pelos pesquisadores) e conclusões, para chegar a teorias e leis" (BORGES, 2007, p. 18).

Em contrapartida, o caminho indicado por outro entrevistado - P3 - centra-se mais no uso da razão enquanto ferramenta para entender ou descobrir algo novo; e podemos associá-lo a também outro pesquisador fundamental para o entendimento moderno de ciência e sua metodologia: Descartes. Os preceitos metodológicos descritos por Descartes (2008), no século XVI, apontam que, se estiver interessado na busca da razão e do conhecimento, qualquer sujeito poderia desenvolver seu modo próprio de analisar e produzir conhecimento. O primeiro dos quatro preceitos de Descartes é duvidar sempre de alguma coisa tomada como verdadeira, até que ela esteja claramente elucidada. Em seguida, dividir o problema em quantas partes forem necessárias, até alcançar uma solução adequada e, então, o terceiro preceito é determinar a organização do pensamento do mais simples e fácil ao mais complexo, passo a passo, "[...] nomeando até mesmo em pensamento uma ordem certa para os objetos, os quais, por sua própria natureza, não sugerem relação de 72 antecedência e sequência" (DESCARTES, 2008, p. 25).

Por fim, seu último preceito pretende a totalidade, ao afirmar a necessidade de fazer revisões tão gerais, pensando todos os aspectos envolvidos no que vem sendo estudado, até que seja assegurado que nada esteja fora da análise (DESCARTES, 2008). Neste contexto, um entrevistado - P3 - comentou que, para ele, o método pode ser conectar coisas ou fatos que antes pareciam soltos e, assim, gerar alguma nova descoberta, pelo uso de raciocínio.

Por este viés, entendemos que, para esse mesmo entrevistado, a geração de um produto "novo" e publicável - a segunda parte desse primeiro enunciado - pode ser "dar um sentido" para o objeto que vem sendo analisado e que, antes, parecia disperso e desconectado. Ao mesmo tempo, esse produto é fortemente vinculado às publicações nas áreas científicas, como podemos ver nos exemplos de enunciações trazidas abaixo.

Na área de Ciências Agrárias, ou seja, de plant science, tem uma inserção muito forte. Se tem uma conexão muito forte, e essa conexão forte talvez esteja ligada ao enorme impacto que nós temos, do ponto de vista econômico e também social. Hoje, vamos dizer assim, grande parte da pesquisa que é feita é voltada para, e de 
Lavínia Schwantes | Paula Corrêa Henning | Paula Regina Costa Ribeiro

alguma forma, tem impacto significativo na agricultura [...] Mas isso é ciência aplicada, ciência não pode ser aplicada [...] Aquela conversa [...] Mas eu sinto muito confortável, porque eu faço ciência básica aqui de montão. A gente publica bastante, tem um monte de coisa, tem impacto. Mas, curiosamente, se você for separar e ver a contribuição da ciência das plantas ou ciências agrárias no mundo, hoje a gente responde por 9\% da ciência produzida no mundo na área (P3, 2011$)$.

Acabou de ser aprovado o mestrado profissional [...]. Um outro tipo de problema é você chegar no final do doutorado desses alunos [ex professores] e falar: 'Ah, ok, mas quantos papers tiveram por conta do conceito da Capes?' Aí, o mestrado profissional na verdade é um produto. Na verdade, estão fazendo um excelente trabalho, mas que o produto final não é um artigo científico (P2, 2011 ).

Além dessas enunciações, citamos ainda a seguinte cena para a constituição deste enunciado: P1, durante a entrevista, mostra um artigo que faz correlação entre o número de doutores e a quantidade de trabalhos publicados formando uma linha reta, ou seja, um é função direta do outro.

Na maioria dessas enunciações, percebemos a necessidade de publicação dos resultados como marcador da manutenção de potência da ciência nos dias atuais. $\bigcirc$ que legitima um ou outro grupo como parte de uma comunidade científica engajada e produtiva é o número de publicações de qualidade que produzem. Loredana Susin (2007) percebe a relevância da publicação para manutenção de um grupo de pesquisa na "ordem do dia" da produção científica. Muitas vezes, toda a pesquisa direciona-se a este fim: a produção de dados publicáveis. Ao acompanhar o cotidiano de pesquisa em um laboratório de bioquímica, a autora procurou mostrar a rede de elementos que estavam atuando na construção dos conhecimentos científicos nesse laboratório, enfatizando a articulação dos elementos de diferentes ordens (como, por exemplo, os seminários de grupo e as práticas associadas ao laboratório) na produção, na circulação e na utilização dos produtos científicos.

Diferente de uma concepção de ciência idealizada que descobriria todo o conhecimento disponível e traria a solução para todos os problemas do mundo, como almejava Bacon (1984), no século XVI; ou, ao contrário, diferente de uma visão negativa de que os avanços científicos foram os grandes geradores de guerras, genocídios e dos problemas ambientais vivenciados hoje, o intuito atual de grande parte da produção da ciência tem se tornado 
gerar publicações. Bruno Latour e Steve Woolgar (1997, p. 44, grifo dos autores) resumem essa produção: "[...] sobre ela [a curva de um gráfico no papel] que se debruçam os pesquisadores em busca de um 'significado'. Ela torna-se o 'dado' em uma demonstração ou em um artigo". Os dados são conseguidos depois de toda uma técnica bem desenvolvida nos laboratórios e discutida nos grupos de pesquisa.

Podemos perceber que, para os primeiros envolvidos na rede, a conexão entre ciência, método e publicações é crucial para o bom andamento da produção científica, resumido no enunciado fazer ciência envolve um caminho e a geração de produtos "novos" e publicáveis. E, estendendo isso aos cursos, revela-se a importância que os professores/cientistas, que iniciaram a RNEC/ NT, atribuem à experimentação e ao método científico para o acesso à ciência e, consequentemente, para a melhoria da educação em ciência.

No sentido da discussão trazida aqui, este enunciado, produzido a partir das falas dos entrevistados, nos conduz a um entendimento moderno de saber científico calcado nos princípios descartianos e baconianos. E, por outro lado, afirma uma característica contemporânea da produção do saber científico: a publicação.

74 Consideramos importante salientar que, nas análises que procuramos fazer aqui, entendemos que a formação de um campo de saber, como o científico, se dá pela organização dos discursos numa trama de relações de força. Esses discursos - formados de enunciados - não estiveram sempre prontos no espaço, esperando apenas ser "descobertos", nem foram apenas resultado da mente privilegiada de alguns sujeitos. E, sim, esses discursos foram inventados, a partir de inúmeros jogos de força, interesses e lutas, que fizeram com que os discursos, procedimentos e mecanismos que regulam a determinação do que é considerado falso e do que é considerado verdadeiro se constituíssem campos de saber, como aqui a ciência (FOUCAULT, 2009a). Dessa forma, entendemos que esses campos de saber possuem elementos e práticas discursivas que podem constituir-se em discursos específicos de cada campo, nomeados por sua forma e rigor, pelos objetos de que se ocupam, pelos tipos de enunciação que põem em jogo, assim como pelos conceitos e estratégias que utilizam (FOUCAULT, 2009b). 


\section{Enunciado 2: A formação do cientista na díade inatismo e empirismo}

Outra parte importante do discurso inicial de ciência da Rede tem relação com a metodologia dos cursos que os primeiros grupos desenvolviam no início da RNEC/NT. Essa metodologia inicial inclui a elaboração pelos participantes (estudantes de Ensino Médio ou professores da rede pública) de quaisquer perguntas sobre um assunto amplo predeterminado (por exemplo, célula, ou alimentos, ou vegetais). Um dos entrevistados - P2 - explicou que, dessas perguntas, cada grupo de participantes deve escolher a que será pesquisada experimentalmente no decorrer de três dias com ajuda de alguns monitores. Esses monitores questionam os grupos, não emitindo as respostas prontas, mas instigando-os a pensar em como poderiam testar as ideias iniciais, no que poderia acontecer se as testassem, e quais alternativas fariam caso dessem errado. Os participantes elaboram uma série de protocolos experimentais e vão testando suas hipóteses com os materiais disponibilizados pelos monitores para as experimentações. Por fim, no último dia do curso, os grupos têm de apresentar suas produções e "descobertas", de alguma forma artística, como teatro, música, dança, à sua preferência.

Os participantes que se destacam nesse curso de caráter basicamente experimental são convidados a fazer estágios nos laboratórios de pesquisa. Essa descrição de como se desenvolve o curso aponta uma espécie de exercício, de treinamento no qual os estudantes passam dias criando e executando experimentos. Apontamos, abaixo, algumas das enunciações em que a metodologia e o treinamento ficam evidentes:

Sempre nessa metodologia. [...] Desde que eu comecei, sem pergunta, sem repostas prontas, sem protocolo montado. [...] Com professores e alunos (P2, 2011 ).

Eles fazem as perguntas. Quando eles acabam de fazer as perguntas, a gente revela pra eles: 'Olha, a gente não vai responder nada, nós somos técnicos aqui e estamos apenas para ajudar a responder. O propósito do curso é que vocês criem respostas por vocês mesmos, exercendo a metodologia científica, trabalhando com a metodologia científica, criando hipóteses' (P2, 2011 ).

Na verdade, eles [os professores] estão querendo alunos sentados o tempo inteiro e que não façam perguntas. 'Eles não vão ficar quietos, imagina? Isso vai ficar uma bagunça!' Aí você fala: 'Não, olha 
Discurso sobre a Ciência na emergência histórica da "Rede Nacional de Educação e Ciência"

só, se você pega toda a energia que eles têm, toda a criatividade que eles têm... E foca, na verdade ele vai mergulhar no conhecimento, vai se tornar uma pessoa crítica, que sabe o que é ciência, vai tomar contato com ciência' (P2, 2011 ).

Eu estimulo os alunos a pensar e a propor um projeto. Eles executam aquilo durante o semestre e em cima disso, [...] e por isso, a gente vai desenvolvendo o conhecimento e a discussão em cima da área. Então, o método, ele é muito importante (P3, 2011 ).

Nem todo pós-graduado tem quer ser cientista. $\bigcirc$ conhecimento cresce, o saber cresce continuamente. Então, para você poder absorver o que está acontecendo no mundo, você tem que ter o mínimo de treino (P1, 2011 ).

E aí às vezes eles vão lá e você vê que rolou uma induzida muito forte [por parte dos monitores]. Induzida sempre tem. [...] Quando falam: 'Não, a gente não induz'. Mentira. Na verdade, você induz, você não dá a resposta, mas você vai induzindo. Quando você chega lá [no curso], está conversando com o cara e ele: 'Ah, mas eu queria dosar proteína'. Ele não sabe da existência do reagente, é óbvio que você vai ter que dar o reagente, entendeu? (P2, 20111.

acompanhamento e treinamento para que o sujeito seja adequado e instrumentalizado para o trabalho no laboratório e na pesquisa científica, como os pós-graduandos ensinam aos "jovens talentos", foi um dos pontos discutidos por Susin (2007), quando investigou como se dava a produção do conhecimento científico em um laboratório de bioquímica. Baseando-se nos estudos de Latour e Woolgar (1997), que estudaram a constituição de um artefato científico em um laboratório de pesquisa nos Estados Unidos, a autora aponta toda a rede de elementos que atravessam essa produção. Entre elas, aponta a importância dada a essa formação gradual dos sujeitos da ciência. Há uma preocupação, segundo Susin, com a padronização das técnicas, em especial durante o treinamento de bolsistas novos. Esse movimento aparece nos cursos para alunos como relatado nas enunciações acima.

Também a relação entre monitor e grupo de estudantes torna-se muito estreita e ambos vão estabelecendo as descobertas, as hipóteses e os experimentos em conjunto, sem uma hierarquia preestabelecida entre professor e aluno como na última enunciação de P2. Neste ponto, podemos discutir a relação apontada ao longo da história da ciência mundial entre a teoria e a 
prática na produção do saber científico. Na concepção moderna de ciência, uma não se sustenta sem a outra. $\bigcirc$ empirismo baconiano e o racionalismo descartiano, ambos importantes para a emergência da ciência moderna, articulam-se de forma muito estreita na produção científica atual. Também Paul Feyerabend (2007, p. 210), crítico do método único na produção da ciência, aponta essa relação na produção dos "fatos" científicos. A elaboração do "fato" não se dá apenas na aplicação de uma teoria e de um método, mas também "[...] descobrimos que o aprendizado não vai da observação para a teoria, mas envolve sempre ambos os elementos". Essa articulação, defendida por Feyerabend e sua proposição de uma metodologia pluralista, não é muito presente nas enunciações, visto que a maioria foca no método científico tradicional.

No entanto, ao mesmo tempo que está presente essa concepção do "aprender fazendo", há uma forte menção nas enunciações dos entrevistados sobre a necessidade de os participantes escolhidos para estágio terem "talento" para a ciência. Podemos retomar, inclusive, a nomenclatura do programa que faz menção ao talento: Rede Nacional de Educação e Ciência - Novos Talentos da Rede Pública. Esse termo corresponde ao potencial que temos dentro de nós mesmos, que pode ser explorado de tal forma a ser posto em evidência. A ideia de talento tem respaldo na corrente epistemológica do apriorismo (ou inatismo) que acredita que o ser humano nasce já com o conhecimento programado em sua carga genética (BECKER, 2001). Tudo estaria previsto em sua herança, inclusive aqui, neste contexto, a aptidão para a ciência, como dito nas enunciações abaixo que auxiliam a produção deste enunciado:

Identificar os jovens talentos de verdade, e promover, e ver se a gente consegue, com isso, impactar de forma efetiva o nosso país (P3, 2011$)$.

Mas eu acho que é muito mais urgente trabalhar com os jovens. Eu quero descobrir os Bill Gates, os Mark Zuckerberg [...], eu quero descobrir... (P3, 2011$)$.

E são os alunos, tanto do Ensino Médio quanto da universidade que vão mudar esse país. Porque as pessoas, que já estão de alguma forma 'empregados', estão com a cabeça meio feita, meio estragada. Então, talvez eles não consigam fazer as mudanças que precisam ser feitas. Então, a gente tem que investir, estou iniciando 
Discurso sobre a Ciência na emergência histórica da "Rede Nacional de Educação e Ciência"

outras iniciativas interessantíssimas na tentativa de identificar novos talentos (P3, 2011$)$.

Você vê que os meninos começam a se destacar [...]. Eu costumo dizer que o programa é, [...] para jovens talentosos de baixa renda, mas a gente também diz que não está aqui pra fazer caridade (P2, 2011$)$.

Para o apriorismo, segundo Regina Borges (2007), todo o conhecimento ou potencial para saber encontra-se armazenado em nós, aguardando seu descobrimento. Assim opõe-se ao empirismo, no qual o conhecimento está fora de nós mesmos e é através da experiência e vivência no meio físico que o alcançaremos. Podemos pensar uma possível interligação do idealismo com o platonismo que separava o mundo nas esferas sensível (dos sentidos) e ideal (dos saberes e essências), sendo que, para Platão, esta última esfera era alcançada pelo domínio da razão.

Percebemos, assim, a valorização do "talento" que seria demonstrado pelos meninos durante o desenrolar do curso. Aqueles que se mostravam mais interessados e com a capacidade de formulação de perguntas mais aguçadas eram chamados para estágios no laboratório. No entanto, mesmo com essa primeira concepção idealista, o pleno desenvolvimento do aluno dependia muito do seu empenho nas atividades experimentais, construído no treino do laboratório, discutido anteriormente. Sendo esse aluno ajudado por um pós-graduando que o ensinaria como agir na produção de conhecimento no laboratório, voltamos a perceber a concepção epistemológica empirista no treinamento do sujeito. Ele deve ser acompanhado por um pós-graduando que o ensine tudo o que for necessário. Vemos como as duas concepções - apriorista e empirista - aparecem presentes no desenvolvimento dos cursos e estágios do programa da RNEC/NT.

Assim, percebemos que, para a escolha daqueles que serão os novos cientistas, devemos considerar tanto a aptidão para a ciência quanto a sua boa ałuação junto aos experimentos. Por isso, um segundo enunciado - a formação do cientista na díade inatismo e empirismo - se produz a partir das enunciações, expostas anteriormente e na próxima que traz a díade na mesma fala:

'Quem sabe a gente começa a caçar talentos aqui e botar no laboratório'. Então, eu sugeri aos pós-graduandos, que gostaram muito 
da ideia: pegar os meninos melhores, eles entrevistarem, e trazerem para o laboratório para trabalhar com eles. E o menino ajudaria o pós-graduando fazendo a tese e, ao mesmo tempo, ele tinha que controlar bonitinho o menino, e onde não tivesse como ensinar, ele tinha que arranjar como ensinar (P1, 2011$)$.

Destacamos ainda que, não obstante o treinamento e a tentativa de construção do conhecimento nos cursos, é escolhida a palavra "talento" como central no nome que intitula o programa da RNEC/NT e como uma característica necessária ao bom cientista. Epistemologicamente, isso pode parecer contraditório (BECKER, 2001). No entanto, entendemos que as duas perspectivas responsabilizam o sujeito por sua própria formação, tanto pelo talento que esse apresentaria quanto pelo seu desempenho no treinamento no laboratório.

\section{Enunciado 3: Formação de cientistas pela inclusão social}

Nesta seção, descrevemos este último enunciado, pertencente à mesma formação discursiva que os anteriores, cuja descrição é a própria análise do discurso, já que constituem, segundo Foucault (2009a, p. 124), uma única e mesma coisa - o discurso inicial de ciência da emergência da RNEC/ NT. Retomando o entendimento de enunciado, relembramos que o "[...] enunciado é ao mesmo tempo não visível e não oculto"; assim, este enunciado 3 foi estabelecido a partir das enunciações abaixo:

Então, [... é uma troca porque o menino de baixa renda entra e aí ele vai ser ajudado pelo programa no sentido de receber apoio pra suprir as deficiências dele do ensino, pra tentar ingressar na universidade. Ele vai tomar contato com projeto de pesquisa, então, ele recebe, logo no início, um projeto bem simplesinho, mas que ele está atrelado (P2, 2011).

[conta episódio de meninos na rua vendendo balas no trânsito] Você está fechando a janela, a porta, para as nossas crianças, isso é um horror. Então, começou a me incomodar que era necessário fazer alguma coisa; o que eu sabia fazer era ensinar e educar. Então, me ocorreu que a única coisa que eu posso fazer é ajudar, fazendo o que eu sei fazer; não posso ajudar entrando em ONGs etc, porque não é a minha vocação; e aí comecei o programa. [...] E é esse tipo de pessoa que nós tratamos pra vir trabalhar, pelo 
Discurso sobre a Ciência na emergência histórica da "Rede Nacional de Educação e Ciência"

menos que tem uma chance no curso de férias. Comecei a fazer isso em 1985 (P1, 2011$).$

Identificar os jovens talentos de verdade, e promover, e ver se a gente consegue, com isso, impactar de forma efetiva o nosso país (P3, 2011$)$.

Eu costumo dizer que o programa é [...] para jovens talentosos de baixa renda, mas a gente também diz que não está aqui pra fazer caridade. Pode parecer uma coisa meio grosseira, mas é assim: 'Ah, não é porque ele é pobrezinho que a gente vai lá e vai intervir'. Na verdade, a ideia é ver se realmente tem algum talento também. Então, se ele tiver talento e for de família pobre, é que a gente vai apostar de verdade (P2, 2011 ).

A questão da inclusão social entrou muito fortemente na constituição da RNEC/NT e nos cursos, desde seu início, e aparece explícita no seu objetivo no site - "[...] a melhoria das condições de ensino de ciências a jovens de todo o país" (REDE, 2015). P1, já inserido como pesquisador reconhecido na área de Bioquímica, afirma que sua ideia inicial para o programa foi de estimular os jovens a encantarem-se com a carreira científica. Historicamente, 80 no Brasil, durante período pré-republicano, já chegavam as concepções filosóficas europeias que enfatizavam a importância da ciência para o avanço de um país (BRAGA, GUERRA, REIS, 2011 ).

Marilda Maganimi (2009, p. 10) traz a trajetória da ciência e do ensino no período da República Velha que se deu através de "alguns espaços institucionais onde se cultivava a Ciência e a tecnologia, destacando alguns de seus pesquisadores e demonstrando preocupação de evidenciar a importância dessas áreas para o desenvolvimento da sociedade". Já no período de governo de Getúlio Vargas - conhecido como "pai do povo" - nas décadas de 30 e 40 do século XX, embora, por um lado, esteja vinculado a perspectivas ditatoriais europeias; por outro, possibilitou a emergência de políticas sociais e trabalhistas no país. A partir deste período, passou-se a olhar para os menos favorecidos como um problema de Estado.

Segundo Kamila Lockmann (201 1), antes disso, até meados do século XIX, somente se desenvolviam práticas de assistência aos necessitados como atos de caridade ao próximo e essas práticas eram desenvolvidas de forma individualizada como doações e auxílios materiais. Anteriormente ao período de determinação de direitos ao cidadão de Vargas, o país passou de uma fase 
de assistência caritativa para uma de filantropia higiênica cuja preocupação direcionava-se aos efeitos que a pobreza traria para a sociedade como um todo.

Desde o estabelecimento dos direitos do cidadão e do trabalhador, a ascensão social das classes brasileiras menos favorecidas tem sido discutida no país, com diferentes ênfases nos diferentes governos eleitos pelo voto desde a década de 1990. De diferentes formas, são propostos projetos de inclusão social como o da RNEC/NT. Esse viés da inclusão esteve desde o início vinculado ao programa e tem se tornado uma das forças para sua permanência no cenário nacional de pesquisa em ciência e educação.

Este terceiro enunciado compõe-se a partir de enunciações que trazem a divulgação da ciência e a inserção na atividade científica como forma de equilíbrio social no país. Assim, os primeiros participantes apontam a inclusão dos jovens carentes na "vida" científica dos laboratórios das universidades públicas como forma de ascensão social por meio do acesso à ciência. As enunciações abaixo são características desse entendimento.

A ideia geral não era dar a mãozinha para o menino, esse negócio paternalista. Era botar o menino na universidade pública, onde ele possa fazer uma carreira (P1, 2011$).$

Então, uma coisa que naquela época [início da Rede] foi considerado e que eu continuo tentando valorizar até hoje, é que a gente tenta pegar os meninos que se destacam no curso, mas que são de baixa renda (P2, 2011$)$.

A ideia geral era a seguinte: tentar fazer alguma coisa que a gente faz realmente; se você der uma receita de bolo pro menino fazer, você faz o experimento assim, assim, assim, assim, assado, é uma receita de bolo que não é o que nós fazemos (P1, 2011 ).

Atualmente, no Brasil, intensificou-se a questão da inclusão social desde os governos federais do século XXI, através da associação entre os programas de assistência monetária e a frequência dos jovens à escola (LOCKMANN, 201 1). Mesmo que a intenção de inclusão social esteja presente desde a emergência da RNEC/NT, é neste período citado pela autora que essa intenção recebe interesse governamental, sendo objeto de programa de governo e de financiamento de projetos por diferentes organizações como a Capes. 
A Capes, fundada em 1951 junto ao CNPq, "[...] se notabilizou, apesar dos poucos recursos, na formação de docentes das escolas superiores por meio de cursos, eventos e concessão de bolsas de estudos" "MOTOYAMA, 2009 , p. 5 1). Atualmente, além de financiar o programa da Rede, a Capes criou edital baseado nos princípios da mesma, em especial, devido à característica de inclusão social na ciência presente no programa.

primeiro edital "novos talentos" aberto a todas as universidades e institutos do país, ocorreu em 2010 (CAPES, 2014) cujo objetivo visou apoiar a realização de atividades extracurriculares - cursos, oficinas ou atividades equivalentes - no período de férias das escolas públicas ou em horário que não interferisse na frequência escolar. Esse edital visa, ainda, atender tanto alunos do Ensino Médio e Fundamental quanto professores da rede pública, os quais participariam das atividades sob a orientação de um professor qualificado ou um aluno de pós-graduação stricto sensu. Salientamos aqui a forte vinculação desse edital às proposições da RNEC/NT (REDE, 2015).

Entendemos que o enunciado da inclusão dá sustentabilidade ao discurso inicial de ciência da RNEC/NT, pois é através dela que os jovens carentes podem ser inseridos no universo moderno da ciência, possibilitando, 82 por mais desse aprender a "fazer ciência", melhores condições de vida para eles.

Com essa análise, podemos compreender o alcance que os enunciados do discurso inicial de ciência da RNEC/NT apresentam desde sua emergência até os dias atuais. Como afirma Foucault (2009), os discursos constituem-se enquanto saber na história, a partir de condições de possibilidades específicas e, portanto, tendem a se modificar de acordo com as mudanças políticas, econômicas que ocorrem em nossa sociedade. Assim os discursos e os saberes atualizam-se. Neste caso, vemos que o primeiro enunciado traz as raízes modernas do saber científico, bem como as atualiza na contemporaneidade - por meio da necessidade de publicação. $\bigcirc$ segundo enunciado enfoca também um viés moderno de treinamento em uma metodologia científica específica ao mesmo tempo que enfoca a essência talentosa dos sujeitos para que sejam cientistas notáveis. E, por fim, o terceiro enunciado demarca a intenção política do discurso inicial ao trazer a questão da inclusão para a esfera da ciência. Possibilita-se, por essa construção discursiva, baseada nestes três enunciados, o entendimento inicial de ciência da RNEC. 


\section{Considerações finais}

Na escrita deste artigo, podemos dizer que, no sentido que Foucault (2009) dá à história, não existem pontos de origem para algum fato, mas condições de possibilidade que, ao se articularem, fazem emergir o que hoje entendemos ser o discurso inicial da RNEC/NT.

Dessa forma, no primeiro enunciado que destacamos para imprimir visibilidade ao discurso de ciência na emergência da Rede Novos Talentos, trazemos a relevância de um método na produção da ciência proposta por ela. Em especial, por esta Rede ser formada por pesquisadores da área das Ciências Biológicas, esse ponto é relevante por centrar a grande maioria das ações dos grupos na experimentação, considerada a principal metodologia a possibilitar o desenvolvimento e "descoberta" de possíveis jovens cientistas.

Noutro enunciado, apontamos o contexto epistemológico do objetivo e da metodologia utilizada pela Rede, pela discussão do talento e do treinamento necessários à formação dos jovens cientistas. Ao mesmo tempo que o título da RNEC/NT foca na questão do talento, que é sustentada pela perspectiva epistemológica inatista, toda a metodologia empregada nos cursos mostra uma ênfase na perspectiva do construtivismo.

E o último enunciado tem relação com o fato de o programa proporcionar uma melhoria ao acesso à ciência a jovens carentes, ou seja, tem um intuito de inclusão social. Nos últimos anos, a inclusão tem se mostrado como um fator determinante para a permanência dos princípios da Rede sob a forma de política governamental. Incluímos este terceiro enunciado no discurso inicial de ciência, pois ele se constitui como parte importante do entendimento de ciência dos entrevistados, isto é, aquela de que o discurso científico deve ser do alcance de todos.

Acreditamos que a constituição deste discurso sobre a ciência auxilia a divulgação da Rede e de suas potencialidades, além de configurar uma possibilidade de entender os diferentes modos como a ciência é entendida atualmente. Destacamos, ainda, em outro artigo (SCHWANTES; HENNING; RIBEIRO, 2015), que muitos grupos, a partir desse discurso inicial, têm atualizado o discurso de ciência da RNEC/NT, desenvolvendo-o junto aos seus cursos na formação continuada de professores. Por isso, podemos afirmar que 
tem se produzido um modo de entender a ciência muito particular na Rede a partir desse discurso inicial, mas que não se encerra nele.

Por fim, com esta análise da constituição do discurso inicial da RNEC/NT, esperamos colaborar para consolidação dos objetivos da mesma. Entendemos que os enunciados aqui problematizados são potentes modos de desenvolver e fabricar a ciência na atualidade.

\section{Notas}

1 A Prova Brasil é uma avaliação-diagnóstico realizada a cada dois anos e aplicada em escolas públicas urbanas e rurais que tenham no mínimo 20 estudantes matriculados no quinto e no nono anos (quarta e oitava séries) do ensino fundamental. $\bigcirc$ desempenho nesta prova também subsidia o cálculo do Índice de Desenvolvimento da Educação Básica (ldeb), ao lado das taxas de aprovação nessas esferas.

2 Comumente essa RNEC/NT é também popularmente chamada apenas "Rede" ou "Novos Talentos" ou "Jovens Talentosos".

3 Desde o início de desenvolvimento do programa da RNEC/NT em 1985 até aproximadamente o final do século XX, apenas UFRJ e UNICAMP realizavam os cursos e os estágios em laboratórios de pesquisa. Depois, outros grupos de diferentes universidades ou institutos federais ou estaduais foram sendo convidados.

4 Na perspectiva de formação discursiva foucaultiana, o nome próprio do autor não importa tanto quanto a sua posição no campo discursivo. Por isso, neste texto, utilizamos a denominação P, de pesquisador, acompanhada por um número apenas como forma de identificar as enunciações comuns a cada um dos três coordenadores, que juntas possibilitam a instauração do discurso inicial de Ciência da RNEC/NT.

\section{Referências}

ANDRADE, Sandra dos Santos. A entrevista narrativa ressignificada nas pesquisas educacionais pós-estruturalista. In: MEYER, Dagmar Esther; PARAISO, Marlucy Alves (Org.) Metodologias de pesquisa pós-críticas em educação. Belo Horizonte: Mazza, 2012.

BACON, Francis. Novum Organum: verdadeiras indicações acerca da interpretação da natureza. São Paulo: Abril cultural, 1984. (Coleção os Pensadores).

BECKER, Fernando. Educação e construção do conhecimento. Porto Alegre: Artmed, 2001.

BORGES, Regina Maria Rabello. Em debate: cientificidade e educação em ciências. Porto Alegre: Editora da PUCRS, 2007. 
BRAGA, Marco; GUERRA, Andrea; REIS, José Carlos. Breve história da ciência universal: a belle-epoque da Ciência. Rio de Janeiro: Zahar, 2011.

BRASIL. Parâmetros Curriculares Nacionais para o Ensino Médio. Brasília: Ministério da Educação/Secretaria de Educação Básica, 1998.

Prova Brasil passa a avaliar alunos também emciências. 10 abr. 2010 . Disponível em: http://portal.mec.gov.br/index.php?option=com_content\&view=article\&id=18579: prova-brasil-passa-a-avaliar-alunos-tambem-em-ciencias\&catid=211. Acesso em: 12 maio 2014.

COORDENAÇÃO de Apoio a Pessoal de Ensino Superior (CAPES). Programa Novos Talentos. 19 ago. 2014. Disponível em: http://www.capes.gov.br/educacao-basica/ novos-talentos. Acesso em: 12 set. 2014.

DESCARTES, René. Discurso sobre o método. Petrópolis: Vozes, 2008.

FEYERABEND, Paul. Contra o método. São Paulo: Editora da Unesp, 2007.

FOUCAULT, Michel. Nietzsche, a genealogia e a história. In: FOUCAULT, Michel. Microfísica do poder. Rio de Janeiro: Graal, 2009.

Verdade e poder. In:

Microfísica do poder. São Paulo: Graal, 2009a.

Arqueologia do saber. Rio de Janeiro: Forense Universitária, $2009 \mathrm{~b}$.

A ordem do discurso. São Paulo: Loyola, 2011.

HENNING, Paula Correa. A modernidade líquida e o borramento de fronteiras no campo das ciências. Revista Uniso, Sorocaba, v. 36, n. 1, p. 53-65, jun. 2010.

LATOUR, Bruno; WOOLGAR, Steve. Vida de laboratório: a produção dos fatos científicos. Rio de Janeiro: Relume Dumará, 1997.

LOCKMANN, Kamila. As políticas de assistência social na educação escolarizada: estratégias da governamentalidade neoliberal. 2011.138f. Tese (Doutorado em Educação) - Programa de Pós-Graduação em Educação, Universidade Federal do Rio Grande do Sul, Porto Alegre, 2011.

MAGANIMI, Marilda. 1921 a 1940: a percepção do futuro no intervalo entre as guerras. Revista Scientific American Brasil, São Paulo, v. 2, p. 10-28, jun. 2009.

MOTOYAMA, Shozo. 1941- 1952: o nascimento de uma estrela, o despontar da Ciência no país. Revista Scientific American Brasil,São Paulo, v. 2, p. 29-5 1, jun. 2009. 
P1. Entrevista. Rio de Janeiro, 28 jul. 2011.

P2. Entrevista. Rio de Janeiro, 28 jul. 2011.

P3. Entrevista. Campinas, 07 dez. 2011.

REDE Nacional de Educação e Ciências. Novos talentos da rede pública. Disponível em: http://www.educacaoeciencia.net.br/site_on/index.php?option=com_content\&view=articl e\&id=1\&ltemid=107. Acesso em: 15 mar. 2015.

SCHWANTES, Lavínia; HENNING, Paula Corrêa; RIBEIRO, Paula Regina Costa. "Fazer o desconhecido ser descoberto": atualização nos modos de enunciar a ciência nos grupos da região sul da Rede Nacional de Educação e Ciência - novos talentos da rede publica (RNEC/NT). Revista Ensaio Pesquisa em Educação em Ciências, Belo Horizonte, v. 17, n. 1, p.173-191, jan./abr. 2015.

SHAPIN, Steve. Nunca pura: estudos históricos da ciência como se fora produzida por pessoas com corpos, situadas no tempo, no espaço, na cultura e na sociedade. Belo Horizonte: Finotraço, 2013.

SOKAL, Alan; BRICMONT, Jean. Imposturas intelectuais: o abuso da ciência pelos filósofos pós-modernos. Rio de Janeiro: Record, 2010.

SUSIN, Loredana. Como acontece a construção do conhecimento científico em um laboratório de pesquisa? In: WORTMANN, Maria Lucia; SANTOS, Luis Henrique Sacchi; RIPOLL, Daniela, SOUZA, Nadia Geisa Silveira de; KINDEL, Eunice Aita Isaia. Ensaios em estudos culturais educação e ciência. Porto Alegre: Editora da UFRGS, 2007.

WORTMANN, Maria Lucia Castagna; VEIGA-NETO, Alfredo José. Estudos culturais da ciência e educação. Belo Horizonte: Autêntica, 2001.

Profa. Dra. Lavínia Schwantes Correio Universidade Federal do Rio Grande Instituto de Educação Programa de Pós-Graduação em Educação em Ciências Grupo de Estudos Educação, Cultura, Ambiente e Filosofia (GEECAF) E-mail |laviniasch@gmail.com 
Profa. Dra. Paula Corrêa Henning Universidade Federal do Rio Grande Instituto de Educação

Programa de Pós-Graduação em Educação em Ciências Grupo de Estudos Educação, Cultura, Ambiente e Filosofia (GEECAF) E-mail | paula.c.henning@gmail.com

Profa. Dra. Paula Regina Costa Ribeiro Universidade Federal do Rio Grande Instituto de Educação Programa de Pós-Graduação em Educação em Ciências Grupo de Estudos Sexualidade e Escola (GESE) E-mail | pribeiro.furg@gmail.com

Recebido 13 mar. 2016 Aceito 14 abr. 2016 